Note

\section{Degeneration of Lymphoid Tissues in Mice with the Oral Intake of Low Molecular Weight Compounds Formed during Oil Autoxidation}

\author{
Motoko Oarada, Teruo Miyazawa, \\ Kenshiro Fujimoto, Emiko Ito, ${ }^{*}$ \\ Kiyoshi TERAO* and Takashi KanedA** \\ Department of Food Chemistry, Faculty of Agriculture, \\ Tohoku University, Sendai 980, Japan \\ ${ }^{*}$ Research Center for Pathogenic Fungi and Microbial \\ Toxicoses, Chiba University, Inohana, Chiba 280, Japan \\ ** Department of Food and Nutrition, Kohriyama \\ Women's College, Kohriyama 963, Japan
}

Received January 28, 1988

Several studies have been reported on the toxicity and nutritive problems associated with lipid peroxides produced during the autoxidation of food oils. ${ }^{1,2)}$ Low molecular weight (LMW) compounds, one type of autoxidation product of oils, are thought to be more toxic than the hydroperoxides to rats and mice. ${ }^{13}$ The main components of LMW compounds are short-chain aldehydes such as 4hydroxy nonenal. ${ }^{3)}$ The effect of these aldehydes on the animals have already been studied in detail. ${ }^{4)}$ For instance, it has been shown that 4-hydroxy nonenal inactivated glucose-6-phosphatase, ${ }^{5}$ and that 2 -alkenals readily reacted with biochemically important groups such as sulphydryl, amino and hydroxyl. ${ }^{4)}$ However, it has not been shown whether the LMW compounds affect the lymphoid tissues. The present paper reports the degenerative effects on such lymphoid tissues as the thymus, spleen and Peyer's patches in mice by the oral intubation of LMW compounds.

LMW compounds were prepared as described previously. ${ }^{3)}$ Of the LMW compounds, 4-hydroxy-2-nonenal, 8-hydroxy methyl octanoate and 10-formyl methyl-9decenoate were identified as the major constituents by gas chromatography-mass spectrometry. ${ }^{3)}$

Male C57 BL/6 mice (6-week old) were purchased from Funabashi Farms Co. (Chiba, Japan). To investigate the toxicity of LMW compounds as components of autoxidized oils and to give the mice an exact amount of LMW compounds, the LMW compounds were quantitatively diluted with fresh methyl linoleate (ML), which dose not cause lymphocyte necrosis. Graded amounts (30, 40, 45 and $50 \mathrm{mg}$ ) of LMW compounds with $100 \mathrm{mg}$ of ML were given once orally to the mice of each group using a stomach tube. $150 \mathrm{mg}$ of $\mathrm{ML}$ was administered alone as a standard. Twenty four hours after administering the
LMW compounds of ML, the mice were killed and prepared for light microscopy by the hematoxylin eosin and periodic acid-schiff staining methods.

Remarkable necrosis of lymphocytes in the thymus and the Peyer's patches, which were scattered on the ileum, was observed after the LMW compounds treatment (Figs. 1 and 2). As shown in Table 1, lymphocyte necrosis was not found when $30 \mathrm{mg}$ of LMW compounds was administered. However, when 40,45 or $50 \mathrm{mg}$ of LMW compounds were dosed, $50 \%, 38 \%$ and $55 \%$, respectively, of the mice examined showed lymphocyte necrosis in their thymus. In the Peyer's patches, necrosis appeared in $25 \%, 25 \%$ and $45 \%$ of the mice to which 40,45 and $50 \mathrm{mg}$, respectively, of LMW compounds had been administered, (Table I). In the spleen, lymphocyte necrosis was not particularly apparent from the LMW compounds, compared with that in the thymus and Peyer's patches. Before the dose of LMW compounds ( $40 \mathrm{mg}$ ) with ML (100 mg), the body weight of the mice was $22.1 \pm 1.1 \mathrm{~g}$ (mean \pm S.D. of 4 mice). At one day after the administration, the body weight was $21.9 \pm 0.6 \mathrm{~g}$, indicating that the body weight had not been affected by the LMW compounds treatment.

This study shows that an oral intake of the LMW

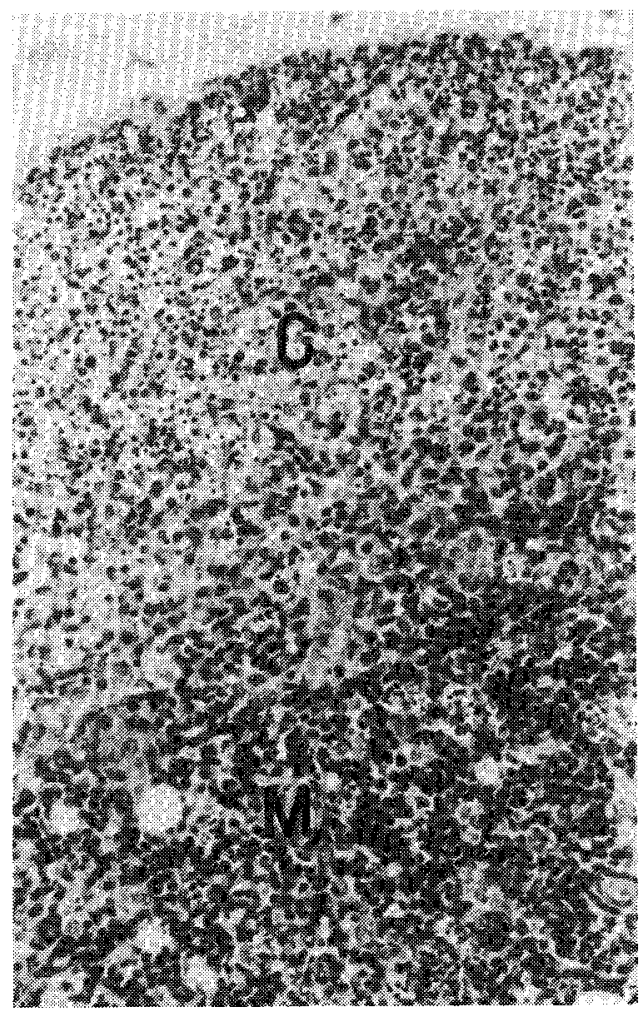

FIG. 1. Thymus from a Mouse Treated with $45 \mathrm{mg}$ of LMW Compounds.

There are numerous lymphocytic debris in the cortical and medullar zones. $(\times 700)$ 


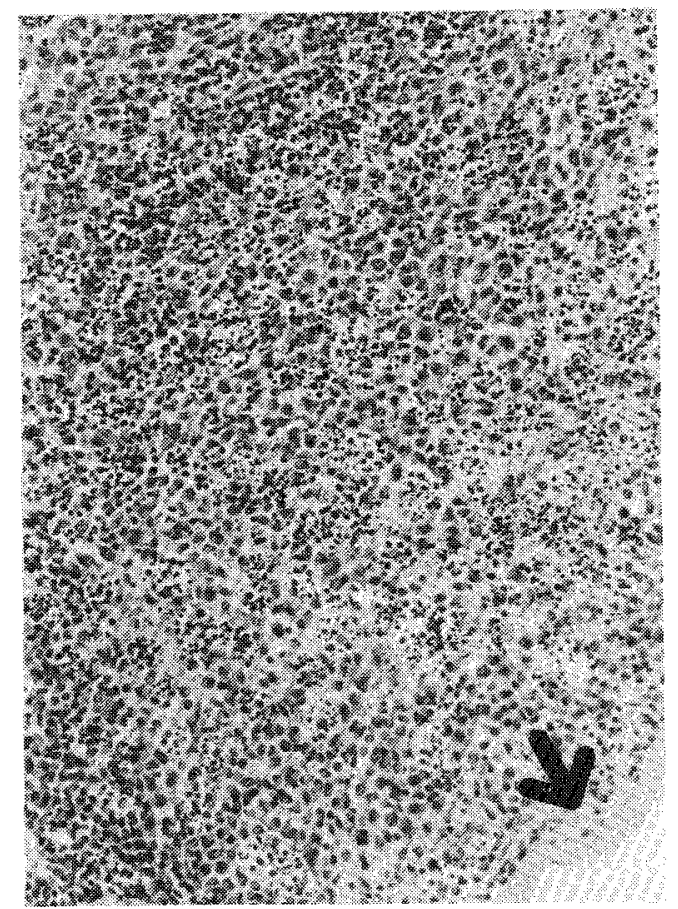

FIG. 2. Peyer's Patch from a Mouse Treated with $45 \mathrm{mg}$ of LMW Compounds.

There are numerous lymphocytic debris in the lymphoid tissue of the Peyer's patch. The thick arrow indicates the muscle layer of the ileum. $(\times 700)$

compounds produced in the autoxidation of oils caused significant damage to lymphocytes in the thymus and Peyer's patches. The authors have already reported that an oral intake of lipid hydroperoxides caused lymphocyte damage in the thymus of mice. ${ }^{6)}$ When $190 \mathrm{mg}$ of methyl linoleate hydroperoxides (MLHPO) was administered, $29 \%$ of the mice showed lymphocyte necrosis in the thymus, and the incidence ratio was increased to $43 \%$ and $50 \%$ in mice to which 270 and $310 \mathrm{mg}$ of MLHPO had been administered, respectively. The present results suggest that LMW compounds damage the lymphocytes more markedly than do the hydroperoxides. This characteristic of LMW compounds may account for their high toxicity.

Acknowledgments. This work was supported in part by a Grant-in-Aid for Scientific Research (No. 62560069) to
Table I. Appearance of Necrosis in Thymus and Peyer's Patches after Oral Administration OF LMW COMPOUNDS TO MiCE

\begin{tabular}{lcc}
\hline & $\begin{array}{c}\text { Thymus } \\
\text { necrosis }\end{array}$ & $\begin{array}{c}\text { Peyer's } \\
\text { patches } \\
\text { necrosis }\end{array}$ \\
\hline [mg/22 g mouse] & {$[\%]^{a}$} & {$[\%]$} \\
LMW 30 mg + ML 100 mg & $0(0 / 7)$ & $0(0 / 7)$ \\
LMW 40 mg + ML 100 mg & $50(4 / 8)$ & $25(2 / 8)$ \\
LMW 45 mg + ML 100 mg & $38(3 / 8)$ & $25(2 / 8)$ \\
LMW 50 mg + ML 100 mg & $55(6 / 1)$ & $45(5 / 1)$ \\
\hline Untreated & $0(0 / 7)$ & $0(0 / 7)$ \\
ML 150 mg & $0(0 / 7)$ & $0(0 / 7)$ \\
\hline
\end{tabular}

a Percentages of mice which showed the thymus or Peyer's patches necrosis to the total mice examined.

Figures in parenthesis indicate the incident number of mice.

LMW compounds, low molecular weight compounds.

T. Miyazawa from the Ministry of Education, Science and Culture of Japan.

\section{REFERENCES}

1) T. Kaneda and T. Miyazawa, "Wld. Rev. Nutr. Diet.," ed. by G. H. Bourne, KARGER, Basel, Switzerland, 1987, pp. 186 197.

2) H. W. Gardner, "Xenobiotics in Foods and Feeds," Vol. 234, ed. by J. W. Finley and D. E. Schwass, American Chemical Society, U.S.A., 1983, pp. $63 \sim 84$.

3) M. Oarada, T. Miyazawa and T. Kaneda, Lipids, 21, 150 (1986).

4) E. Schauenstein, H. Esterbauer and H. Zoller, "Aldehydes in Biological Sỳstems," ed. by J. R. Lagnado, Academic Press, London, 1977, pp. $25 \sim 51$.

5) J. F. Koster, R. G. Slee, A. Montfoort, J. Lang and H. Esterbauer, Free Rad. Res. Commun., 1, 273 (1986).

6) M. Oarada, T. Miyazawa, K. Fujimoto, T. Kaneda, E. Ito and K. Terao, Abstracts of Papers, 4th International Congress on Oxygen Radicals, San Diego, June $27 \sim$ July 3, 1987, M-1, p. 4. 